\title{
Cardiovascular Outcomes of Obesity According to Menopausal Status: A Nationwide Population-Based Study
}

\author{
Bo Kyung Koo ${ }^{1,2}$, Sang-Hyun Park ${ }^{3}$, Kyungdo Han ${ }^{3,4}$, Min Kyong Moon ${ }^{1,2}$ \\ ${ }^{1}$ Department of Internal Medicine, Seoul National University College of Medicine; ${ }^{2}$ Department of Internal Medicine, Seoul \\ Metropolitan Government Seoul National University Boramae Medical Center; ${ }^{3}$ Department of Medical Statistics, College of \\ Medicine, The Catholic University of Korea; ${ }^{4}$ Department of Biostatistics, Soongsil University, Seoul, Korea
}

Background: We estimated the effect of obesity on the incidence of cardiovascular disease (CVD) and mortality in women according to menopausal status.

Methods: Women aged 40 to 69 years under routine health check-ups provided by the National Health Insurance Service in 2009 were followed up till $2018(n=2,208,559)$.

Results: In premenopausal women, a significant increment of mortality rate was found in underweight and obesity class II (hazard ratio [HR], 1.48; 95\% confidence interval [CI], 1.31 to 1.67 ; and $\mathrm{HR}, 1.25$; $95 \% \mathrm{CI}, 1.12$ to 1.39 ) compared to normal body mass index (BMI); overweight and obesity class I did not affect mortality rate. In postmenopausal women, obesity as well as overweight status reduced the risk of mortality compared to normal BMI (HR, 0.86; $95 \% \mathrm{CI}, 0.83$ to 0.88 ; and $\mathrm{HR}, 0.84 ; 95 \% \mathrm{CI}, 0.82$ to 0.86 ). By contrast, there was a linear association between CVD and BMI above the normal range irrespective of menopausal status, which was attenuated in diabetic women.

Conclusion: The current study replicated the J-shaped relationship between BMI and mortality, being more prominent in the postmenopausal group. The risk of CVD was linearly increased as BMI was increased above the normal range irrespective of menopausal status.

Keywords: Obesity; Obesity, abdominal; Body mass index; Waist circumference; Cardiovascular diseases; Mortality

\section{INTRODUCTION}

The phenomenon of obesity paradox has gained attention in recent decades based on the finding that overweight individuals had the lowest risk for total mortality and cardiovascular mortality compared with those with a normal body mass index (BMI) [1]. However, several prospective studies showed that smoking status $[2,3]$ and age $[3,4]$ might be confounders in the association between BMI and mortality. In subjects aged $<65$

Received: 20 July 2021, Revised: 24 September 2021, Accepted: 27 September 2021

Corresponding author: Min Kyong Moon

Division of Endocrinology, Department of Internal Medicine, Seoul Metropolitan Government Seoul National University Boramae Medical Center, 20 Boramae-ro 5-gil, Dongjak-gu, Seoul 07061, Korea

Tel: +82-2-870-2226, Fax: +82-2-831-2826, E-mail: mkmoon@snu.ac.kr years, all-cause mortality was higher in overweight individuals (BMI 25.0 to $26.4 \mathrm{~kg} / \mathrm{m}^{2}$ ) than those with normal BMI irrespective of sex; this was not the case for those aged 65 years or more [3]. There was no difference in the mortality rate among individuals aged $\geq 65$ years with normal BMI and those who were overweight [3], and these results were replicated in a healthy participant group from the National Cancer Institute Cohort [4]. Coexistence of co-morbidities such as diabetes mellitus (DM), chronic obstructive pulmonary disease (COPD), chronic kidney

Copyright $\odot 2021$ Korean Endocrine Society

This is an Open Access article distributed under the terms of the Creative Commons Attribution Non-Commercial License (https://creativecommons.org/ licenses/by-nc/4.0/) which permits unrestricted non-commercial use, distribution, and reproduction in any medium, provided the original work is properly cited. 
disease (CKD), or cancer also affect both of mortality and BMI $[2,5,6]$.

The relationship between mortality and BMI has been reported to be varied according to sex in the Korean population [2] as well as in Caucasians [3]. In women, menopause is an independent risk factor for cardiovascular disease (CVD) $[7,8]$ and CVD-related mortality [9] even in the same age group, menopausal status as well as age should be considered when investigating the effect of bodyweight on CVD or mortality in women; however, the impact of menopausal status on the relationship between BMI and CVD and/or mortality has been rarely reported.

In the current study, the effect of BMI on the incidence of CVD and mortality in Korean women was investigated using the National Health Insurance Service (NHIS) database with stratification according to menopausal status. To elucidate the independent effect on BMI on the outcomes, smoking status, DM, coexistence of co-morbidities, and age as well as menopausal status were also incorporated in the analysis.

The NHIS in Korea covers the claims of $97.0 \%$ of the population in Korea. Accordingly, the NHIS database contains information on almost the entirety of demographic and socioeconomic data and the insurance claims, including prescribed medications and procedures, for the Korean population of approximately 50 million [10]. The present study was performed to estimate the incidence of CVD and mortality in women, according to not only BMI but also waist circumference (WC), using the NHIS data from 2002 to 2018.

\section{METHODS}

\section{Data collection}

We used NHIS database between January 1, 2002 and December 31, 2018. The NHIS offers national health examination programs biennially, and the entire population of women aged 40 to 69 years who underwent routine health check-ups provided by the NHIS during 2009 were selected for the analysis $(n=3,109,506)$. After exclusion of individuals with insufficient data for BMI or menopausal status, with a previous history of hysterectomy, or with a previous diagnosis of myocardial infarction (MI) or stroke during the wash-out period (2002 to 2008), 2,208,559 subjects were finally included (Fig. 1).

Their claims data were followed up till 2018. As previously described [11], the NHIS provided the data after de-identification, and the following data were included: age, sex, diagnosis, date of hospital visits, drug prescribed during inpatient and outpatient visits, the date and the duration of hospital admissions,

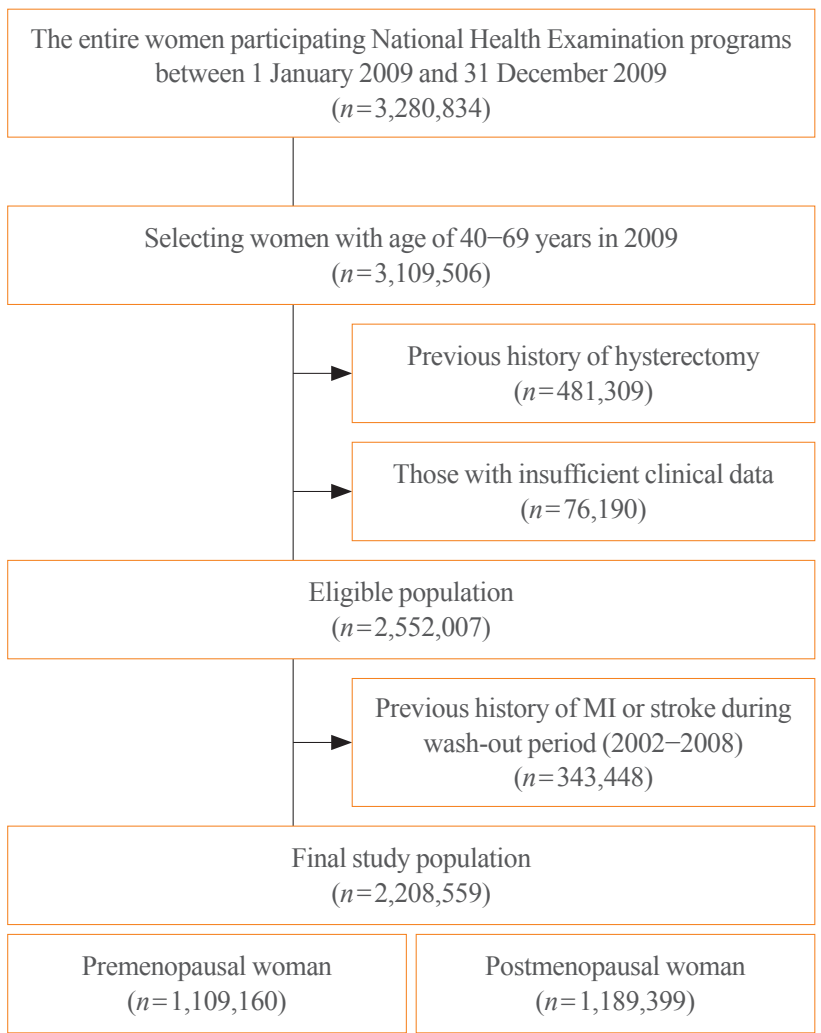

Fig. 1. Consort diagram for study population. MI, myocardial infarction.

medical procedures undertaken, and emergency department visits. Diagnoses were coded according to the International Classification of Disease (10th revision; ICD-10) codes.

The date of death of the participants undergoing the routine health check-ups provided by the NHIS, was retrieved from the National Death Registry maintained by the Korea National Statistical Office.

This study was approved by the Boramae Medical Center Institutional Review Board (07-2019-26). Informed consent was waived by the board.

\section{Definition of obesity and chronic diseases}

BMI was classified based on the World Health Organization (WHO) Asia-Pacific criteria and the Korean Society for the Study of Obesity criteria as follows: BMI 18.5 to $22.9 \mathrm{~kg} / \mathrm{m}^{2}$ indicates normal; BMI 23.0 to $24.9 \mathrm{~kg} / \mathrm{m}^{2}$ is overweight; BMI 25.0 to $29.9 \mathrm{~kg} / \mathrm{m}^{2}$ is obesity class I, and BMI $\geq 30.0 \mathrm{~kg} / \mathrm{m}^{2}$ is obesity class II [12,13]. BMI $27.5 \mathrm{~kg} / \mathrm{m}^{2}$ was also selected for the analysis considering $\mathrm{WHO}$ additionally suggested it as a potential public health action point [14]. WC was measured to the nearest $0.1 \mathrm{~cm}$ from the narrowest point between the lower bor- 
ders of the rib cage and the iliac crest at the end of normal expiration; abdominal obesity was defined as $\mathrm{WC} \geq 85 \mathrm{~cm}[13,15]$.

$\mathrm{DM}$ was defined as the use of anti-diabetic medication, including insulin, under ICD-10 E11-14 at the point of the survey, or an 8-hour fasting plasma glucose level $\geq 126 \mathrm{mg} / \mathrm{dL}$. Dyslipidemia was defined as total cholesterol $\geq 240 \mathrm{mg} / \mathrm{dL}$ or the use of cholesterol-lowering agents under ICD-10 E78. CKD was diagnosed using the estimated glomerular filtration rate (eGFR), which was calculated via the following Modification of Diet in Renal Disease (MDRD) equation: eGFR $\left(\mathrm{mL} / \mathrm{min} / 1.73 \mathrm{~m}^{2}\right)=$ $175 \times(\mathrm{sCr})^{-1.154} \times(\text { age in years })^{-0.203} \times(0.742$ if female $)$, and eGFR $<30 \mathrm{~mL} / \mathrm{min} / 1.73 \mathrm{~m}^{2}$ was defined as CKD [16,17]. COPD was defined as at least one claim under ICD-10 J41, J42, J43, or J44. Presence of comorbidity was defined as the presence of any of cancer, $\mathrm{CKD}$, and COPD, or if the participant is a current smoker.

Menopausal status was assessed was based on the responses to a self-report questionnaire; in the case of menopausal women, status of hormone replacement therapy (HRT) was additionally asked. Subjects who exercised regularly were classified into two groups: moderate-intensity exercise: $\geq 30 \mathrm{~min} /$ day and $\geq 5$ times a week, and vigorous-intensity exercise: $\geq 30 \mathrm{~min} /$ day and $\geq 3$ times a week. Subjects consuming alcohol were classified into three groups: non-drinker, mild drinker (daily alcohol intake, 0 to $29 \mathrm{~g} /$ day), and heavy drinker (daily alcohol intake, $\geq 30 \mathrm{~g} /$ day). Subjects with low income were defined as those on medical aid or with a standardized monthly family income in the lowest $20 \%$ of the entire population. Standardized monthly family income with equivalence scaling was calculated as follows: equivalent income $=$ mean monthly family income $/(\text { family size })^{1 / 2}$.

\section{Study outcomes}

The primary outcome was incident MI, stroke, and all-cause mortality during the follow-up period, from 2009 to 2018. MI was diagnosed based on hospitalization with the primary diagnostic codes ICD-10 I21-22 [18], and stroke was defined according to ICD-10 I63-64 for diagnoses made during hospitalization and according to brain imaging such as computed tomography and magnetic resonance imaging. Previous history of MI or stroke was diagnosed as I21-22 or I63-64, with more than one diagnosis during admission or at outpatient clinics, respectively [18].

\section{Statistical analysis}

All data were analyzed using SAS version 9.3 (SAS Institute Inc., Cary, NC, USA). To compare the clinical characteristics according to menopausal status, independent $t$ test for continuous variables and chi-square test for categorical variables were used. For variables not normally distributed, log-transformation was performed before analysis. The hazard ratio (HR) and 95\% confidence interval (CI) for primary outcomes were calculated using multivariable Cox proportional hazards regression analysis. $P$ values $<0.05$ were considered statistically significant.

\section{RESULTS}

\section{Baseline characteristics}

The mean age of premenopausal $(n=1,019,160)$ and postmenopausal women $(n=1,189,399)$ in the current study was $45 \pm 4$ and $59 \pm 6$ years, respectively $(P<0.001)$. Postmenopausal women were more obese (mean BMI, $24.2 \pm 3.1 \mathrm{~kg} / \mathrm{m}^{2}$ vs. $\left.23.2 \pm 3.1 \mathrm{~kg} / \mathrm{m}^{2}, P<0.001\right)$ and had higher blood pressure (mean systolic blood pressure, $124.4 \pm 15.8 \mathrm{~mm} \mathrm{Hg}$ vs. 117.3土 $14.4 \mathrm{~mm} \mathrm{Hg}, P<0.001$ ) and blood triglyceride (TG) levels (geometric mean TG level, $113.7 \mathrm{mg} / \mathrm{dL}$ vs. $89.0 \mathrm{mg} / \mathrm{dL}, P<0.001)$ compared to those in premenopausal women (Table 1).

The median follow-up duration was 9.3 years: 9,495,469 person-year (PY) and 11,088,205 PY in premenopausal and postmenopausal women, respectively. Stroke, MI, and death were observed in 6,013,6,598, and 7,826 women, respectively, in the premenopausal group, and in 21,302, 30,851, and 35,475 women, respectively, in the postmenopausal group (Supplemental Table S1).

\section{The incidence of MI, stroke, and mortality according to BMI in the premenopausal women}

In the premenopausal women, the event rates of stroke and MI (per 1,000 PY) in those with normal BMI were 0.52 and 0.54, respectively. In these women, there was an increasing trend of risk in $\mathrm{MI}$ and stroke as BMI increased from normal range (Table 2, Fig. 2A, B). Overweight individuals (BMI 23.5 to 24.9 $\mathrm{kg} / \mathrm{m}^{2}$ ) showed a significantly higher risk of both stroke and MI compared to those with normal BMI after adjustment for age, smoking history, alcohol consumption, regular exercise, low income, hypertension, dyslipidemia, CKD, and DM (HR, 1.144; 95\% CI, 1.071 to 1.221 ; and HR, $1.189 ; 95 \%$ CI, 1.117 to 1.266 , respectively).

In contrast, there was a J-shaped association between BMI and mortality in the premenopausal women (Fig. 2C). The nadir of mortality in premenopausal women was found in those who were overweight (HR, 0.959; 95\% CI, 0.906 to 1.016) (Table 2), but this was not statistically different from those with normal 
Table 1. Baseline Characteristics According to Menopausal Status

\begin{tabular}{|c|c|c|c|}
\hline Characteristic & $\begin{array}{l}\text { Premenopausal women } \\
\qquad(n=1,019,160)\end{array}$ & $\begin{array}{l}\text { Postmenopausal women } \\
\qquad(n=1,189,399)\end{array}$ & $P$ value \\
\hline Age, yr & $45.1 \pm 4.1$ & $58.5 \pm 5.8$ & $<0.001$ \\
\hline BMI, $\mathrm{kg} / \mathrm{m}^{2}$ & $23.2 \pm 3.1$ & $24.2 \pm 3.1$ & $<0.001$ \\
\hline Waist circumference, $\mathrm{cm}$ & $75.3 \pm 8.1$ & $79.6 \pm 8.5$ & $<0.001$ \\
\hline Systolic blood pressure, $\mathrm{mm} \mathrm{Hg}$ & $117.3 \pm 14.4$ & $124.4 \pm 15.8$ & $<0.001$ \\
\hline Total cholesterol, mg/dL & $192.8 \pm 39.1$ & $208.8 \pm 43.4$ & $<0.001$ \\
\hline Triglyceride, $\mathrm{mg} / \mathrm{dL}^{\mathrm{a}}$ & $89.0(88.9-89.1)$ & $113.7(113.6-113.8)$ & $<0.001$ \\
\hline HDL-C, mg/dL & $60.5 \pm 36.0$ & $58.2 \pm 35.7$ & $<0.001$ \\
\hline LDL-C, mg/dL & $114.8 \pm 71.4$ & $127.9 \pm 72.1$ & $<0.001$ \\
\hline Fasting plasma glucose, $\mathrm{mg} / \mathrm{dL}$ & $93.7 \pm 18.0$ & $99.1 \pm 23.7$ & $<0.001$ \\
\hline Obesity & $252,687(24.8)$ & $443,426(37.3)$ & $<0.001$ \\
\hline Abdominal obesity & $120,759(11.9)$ & $308,140(25.9)$ & $<0.001$ \\
\hline DM & $37,049(3.6)$ & $136,964(11.5)$ & $<0.001$ \\
\hline Hypertension & $139,603(13.7)$ & $452,014(38.0)$ & $<0.001$ \\
\hline Dyslipidemia & $117,683(11.6)$ & $399,747(33.6)$ & $<0.001$ \\
\hline \multicolumn{4}{|l|}{ CKD } \\
\hline $\mathrm{eGFR}<60 \mathrm{~mL} / \mathrm{min} / 1.73 \mathrm{~m}^{2}$ & $43,443(4.3)$ & $108,725(9.1)$ & $<0.001$ \\
\hline eGFR $<30 \mathrm{~mL} / \mathrm{min} / 1.73 \mathrm{~m}^{2}$ & $12,071(1.2)$ & $15,414(1.3)$ & $<0.001$ \\
\hline COPD & $75,404(7.4)$ & $160,239(13.5)$ & $<0.001$ \\
\hline Cancer & $16,083(1.6)$ & $36,834(3.1)$ & $<0.001$ \\
\hline Smoking history & & & $<0.001$ \\
\hline Non-smoker & $967,597(94.9)$ & $1,145,113(96.3)$ & \\
\hline Ex-smoker & $16,504(1.6)$ & $12,615(1.1)$ & \\
\hline Current smoker & $35,059(3.4)$ & $31,671(2.7)$ & \\
\hline Alcohol drinking history & & & $<0.001$ \\
\hline Never & $731,937(71.8)$ & $1,024,875(86.2)$ & \\
\hline Mild & $275,376(27.0)$ & $157,546(13.3)$ & \\
\hline Heavy & $11,847(1.2)$ & $6,978(0.6)$ & \\
\hline Regular exercise & $176,210(17.3)$ & $236,304(19.9)$ & $<0.001$ \\
\hline Low income & $262,723(25.8)$ & $285,201(24.0)$ & $<0.001$ \\
\hline $\mathrm{WC}, \mathrm{cm}$ & & & $<0.001$ \\
\hline$<65$ & $59,226(5.8)$ & $25,533(2.2)$ & \\
\hline $65-74.9$ & $454,705(44.6)$ & $299,575(25.2)$ & \\
\hline $75-84.9$ & $374,470(37.7)$ & $556,151(46.8)$ & \\
\hline $85-94.9$ & $102,779(10.1)$ & $258,444(21.7)$ & \\
\hline$\geq 95$ & $17,980(1.8)$ & $49696(4.2)$ & \\
\hline BMI, $\mathrm{kg} / \mathrm{m}^{2}$ & & & $<0.001$ \\
\hline$<18.5$ & $28,456(2.8)$ & $20,351(1.7)$ & \\
\hline $18.5-22.9$ & $499,611(49.0)$ & $406,277(34.2)$ & \\
\hline $23.0-24.9$ & $238,406(23.4)$ & $319,345(26.9)$ & \\
\hline $25.0-29.9$ & $220,949(21.7)$ & $391,509(32.9)$ & \\
\hline$\geq 30.0$ & $31,738(3.1)$ & $51,917(4.4)$ & \\
\hline
\end{tabular}

Values are expressed as mean \pm standard deviation, geometric mean ( $95 \%$ confidence interval), or number $(\%)$.

BMI, body mass index; HDL-C, high-density lipoprotein cholesterol; LDL-C, low-density lipoprotein cholesterol; DM, diabetes mellitus; CKD, chronic kidney disease; eGFR, estimated glomerular filtration rate; $\mathrm{COPD}$, chronic obstructive pulmonary disease; WC, waist circumference.

${ }^{a}$ Logarithmic transformation was proceeded for analysis on triglyceride level. 


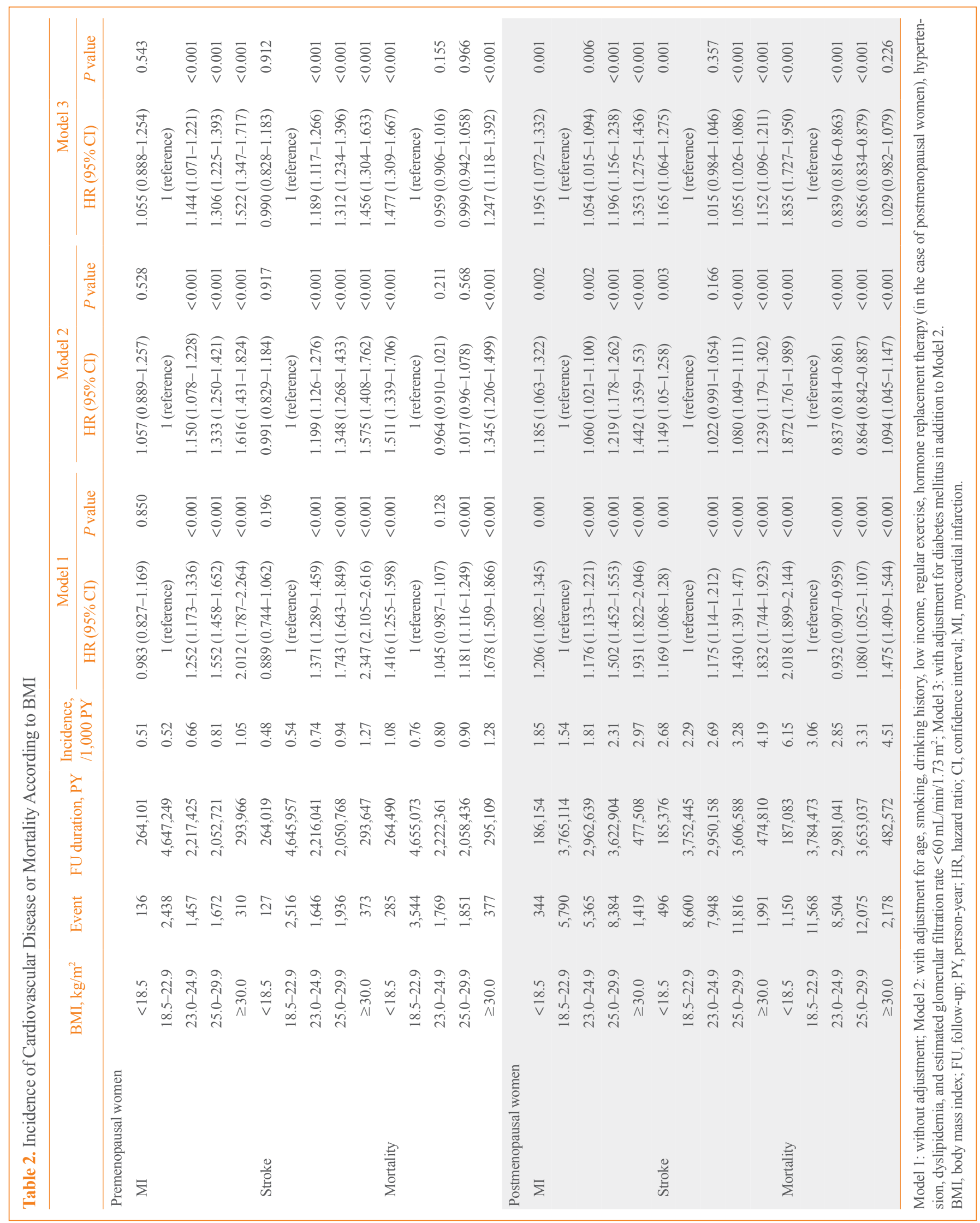



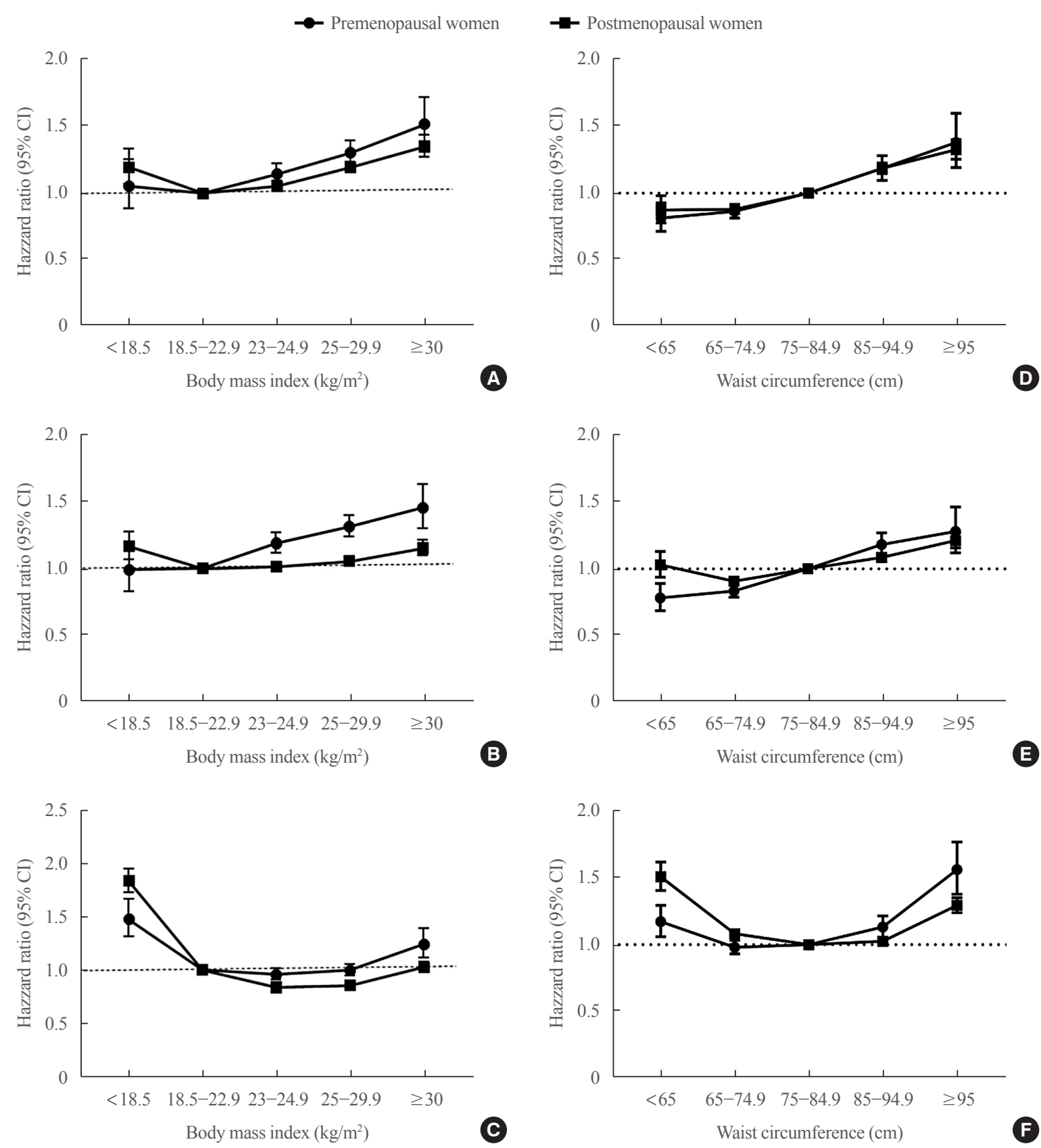

Fig. 2. The risk of myocardial infarction, stroke, and mortality during the follow-up period according to body mass index and waist circumference. Hazard ratios for myocardial infarction (A), stroke (B) and mortality (C) according to body mass index and waist circumference (D, E, F, respectively) after adjustment for age, smoking history, alcohol consumption, regular exercise, low income, hypertension, dyslipidemia, chronic kidney disease, and diabetes mellitus in premenopausal (circle) and postmenopausal women (square). CI, confidence interval.

BMI (Table 2). The mortality rate of women in obesity class I (BMI 25.0 to $29.9 \mathrm{~kg} / \mathrm{m}^{2}$ ) did not differ from that of women with normal BMI (HR, 0.999; 95\% CI, 0.942 to 1.058 ). Women with $\mathrm{BMI}<18.5 \mathrm{~kg} / \mathrm{m}^{2}$ and those with BMI $\geq 30 \mathrm{~kg} / \mathrm{m}^{2}$ (obesity class II) had a significantly higher mortality rate compared to those with normal weight (HR, 1.477; 95\% CI, 1.309 to 1.667; and
HR, 1.247; 95\% CI, 1.118 to 1.392 , respectively) (Table 2). Subsequent classification of the group with BMI $25.0-29.9 \mathrm{~kg} / \mathrm{m}^{2}$ into $25.0-27.5$ and $27.6-29.9 \mathrm{~kg} / \mathrm{m}^{2}$ confirmed that the nadir of mortality in premenopausal women was in those who were overweight (HR in BMI 25.0-27.5 kg/m², 0.968; 95\% CI, 0.907 to 1.034; and HR in BMI 27.6-29.9 kg/m², 1.076; 95\% CI, 
0.984 to 1.177) (Supplemental Fig. S1).

After excluding subjects with histories of malignancy, a similar trend was found (Supplemental Fig. S2A). The nadir of mortality was found in overweight women (HR, 0.952; 95\% CI, 0.896 to 1.012 ), which was not statistically different from that of women with normal BMI (Supplemental Table S2). Additional exclusion of subjects with CKD or COPD and current smokers also confirmed the lowest mortality rate to be in those who were overweight (HR, 0.951; 95\% CI, 0.890 to 1.016 ) (Table 3, Supplemental Fig. S2A). In premenopausal women with comorbidities, the nadir of mortality was found in those with BMI 25.0 to $29.9 \mathrm{~kg} / \mathrm{m}^{2}$ (HR, 0.972; 95\% CI, 0.864 to 1.093), which was not statistically different from that in normal BMI. Furthermore, in premenopausal women with comorbidities, the mortality rate of women with $\mathrm{BMI} \geq 30 \mathrm{~kg} / \mathrm{m}^{2}$ was not statistically different from that of women with normal BMI (HR, $1.154 ; 95 \%$ CI, 0.933 to 1.428$)$.

\section{The incidence of MI, stroke, and mortality according to BMI in postmenopausal women}

In postmenopausal women, the trend of the risk of MI, stroke, and mortality according to BMI was similar to that in premenopausal women. There was an increasing risk of MI and stroke in overweight and obese women compared to that in women with normal weight (Table 2, Fig. 2A, B). Even individuals who were overweight (BMI 23.5 to $24.9 \mathrm{~kg} / \mathrm{m}^{2}$ ) showed a significantly higher risk of MI compared to those with normal BMI, after adjustment for age, smoking history, alcohol consumption, regular exercise, low income, hypertension, dyslipidemia, CKD, and DM (HR, 1.054; 95\% CI, 1.015 to 1.094). The risk of stroke significantly increased past the obesity range of BMI ( $\geq 25 \mathrm{~kg}$ ) $\mathrm{m}^{2}$ ) (Table 2). However, age-stratification showed that in women aged 60 to 69 years, the risks of MI and stroke in the overweight group were not different compared to those for women with normal weight (HR, 1.011; 95\% CI, 0.964 to 1.060; and HR, 0.976; 95\% CI, 0.941 to 1.013, respectively) (Supplemental Table S3).

In the case of overall mortality, the nadir of mortality found in overweight women was more prominent in the postmenopausal group compared to that in the premenopausal group, and the mortality in overweight women was significantly lower than that in women with normal BMI (HR, 0.839; 95\% CI, 0.816 to 0.863) (Fig. 2C). Furthermore, women with BMI 25.0 to 29.9 $\mathrm{kg} / \mathrm{m}^{2}$ (obesity class I) also had a significantly lower mortality than women with normal BMI (HR, 0.856; 95\% CI, 0.834 to 0.879 ); even in those with obesity class II (BMI $\geq 30.0 \mathrm{~kg} / \mathrm{m}^{2}$ ), the risk of mortality was not different compared to that seen in those with normal BMI (HR, 1.029; 95\% CI, 0.982 to 1.079) (Fig. 2C). The mortality rate of those with BMI $<18.5 \mathrm{~kg} / \mathrm{m}^{2}$ was $83.5 \%$ higher compared to that in those normal BMI (HR, 1.835 ; $95 \%$ CI, 1.727 to 1.950 ) (Table 2). Significantly lower mortality risk in overweight and obese women and significantly higher mortality in underweight women compared to women with normal BMI were found irrespective of the presence or the absence of comorbidities (Table 3, Supplemental Fig. S2B). The reduction of overall mortality in those with BMI 23.0-24.9 and $25.0-29.9 \mathrm{~kg} / \mathrm{m}^{2}$ compared to the normal-weight population was more prominent with increasing age (Supplemental Table S3). In postmenopausal women aged 60 to 69 years, the HRs of mortality of women with BMI $23.0-24.9$ and $25.0-29.9 \mathrm{~kg} / \mathrm{m}^{2}$ were 0.829 (95\% CI, 0.802 to 0.858 ) and 0.837 (95\% CI, 0.811 to 0.863$)$, respectively.

\section{Differences in the effect of BMI on the outcomes according to DM}

Subsequent stratified analysis according to DM showed that the risks of MI, stroke, and mortality according to BMI found in the entire population were also replicated in non-diabetic women irrespective of menopausal status (Table 4, Fig. 3). However, in diabetic women, there was no significant increment in the risk of MI or stroke in those with BMI above the normal range (Table 4, Fig. 3A, B). Furthermore, among diabetic postmenopausal women, the risks of $\mathrm{MI}$ and stroke were significantly lower in women with BMI 25.0 to $29.9 \mathrm{~kg} / \mathrm{m}^{2}$ compared to those in women with normal BMI (Table 4).

The nadir in mortality among the diabetic women was found in those with BMI 25.0 to $29.9 \mathrm{~kg} / \mathrm{m}^{2}$, both in the premenopausal and the postmenopausal groups (HR, $0.689 ; 95 \% \mathrm{CI}, 0.562$ to 0.844; and HR, $0.722 ; 95 \% \mathrm{CI}, 0.683$ to 0.763 , respectively) (Fig. 3C). Furthermore, among the postmenopausal women with DM, being in obesity class II (BMI $\geq 30 \mathrm{~kg} / \mathrm{m}^{2}$ ) significantly decreased the risk of mortality compared to having normal weight (HR, 0.846; 95\% CI, 0.778 to 0.919 ).

\section{The risk of MI, stroke, and mortality according to WC}

Subsequently, we compared the risk of MI and stroke according to WC and found that abdominal obesity significantly increased the risk of both stroke and MI, irrespective of menopausal status even after adjustment for age, smoking, drinking history, low income, regular exercise, HRT, hypertension, dyslipidemia, CKD, and DM ( $P$ for trend $<0.001$ in all) (Fig. 2D, E, Supplemental Table S4). Even for those within the normal range of 


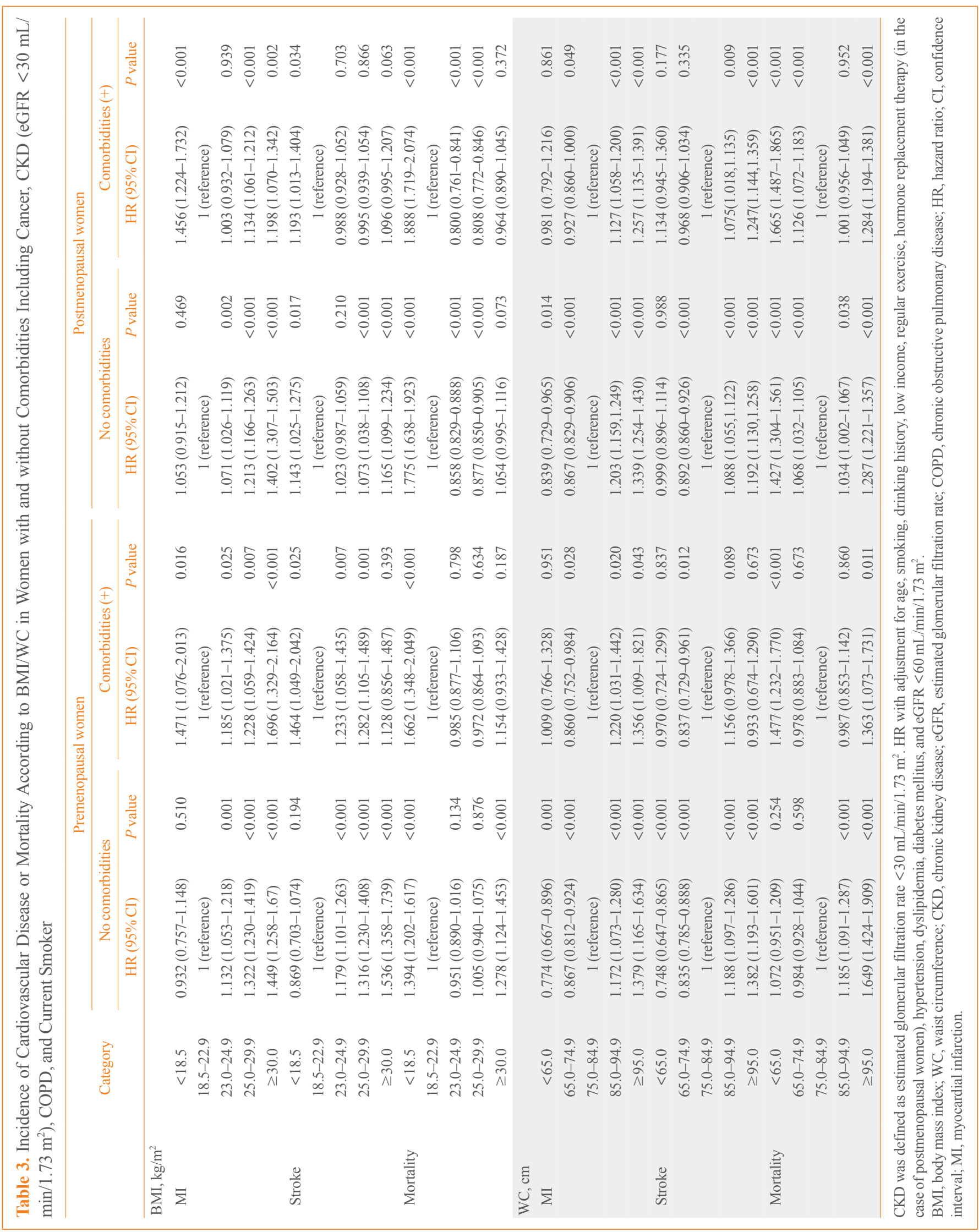




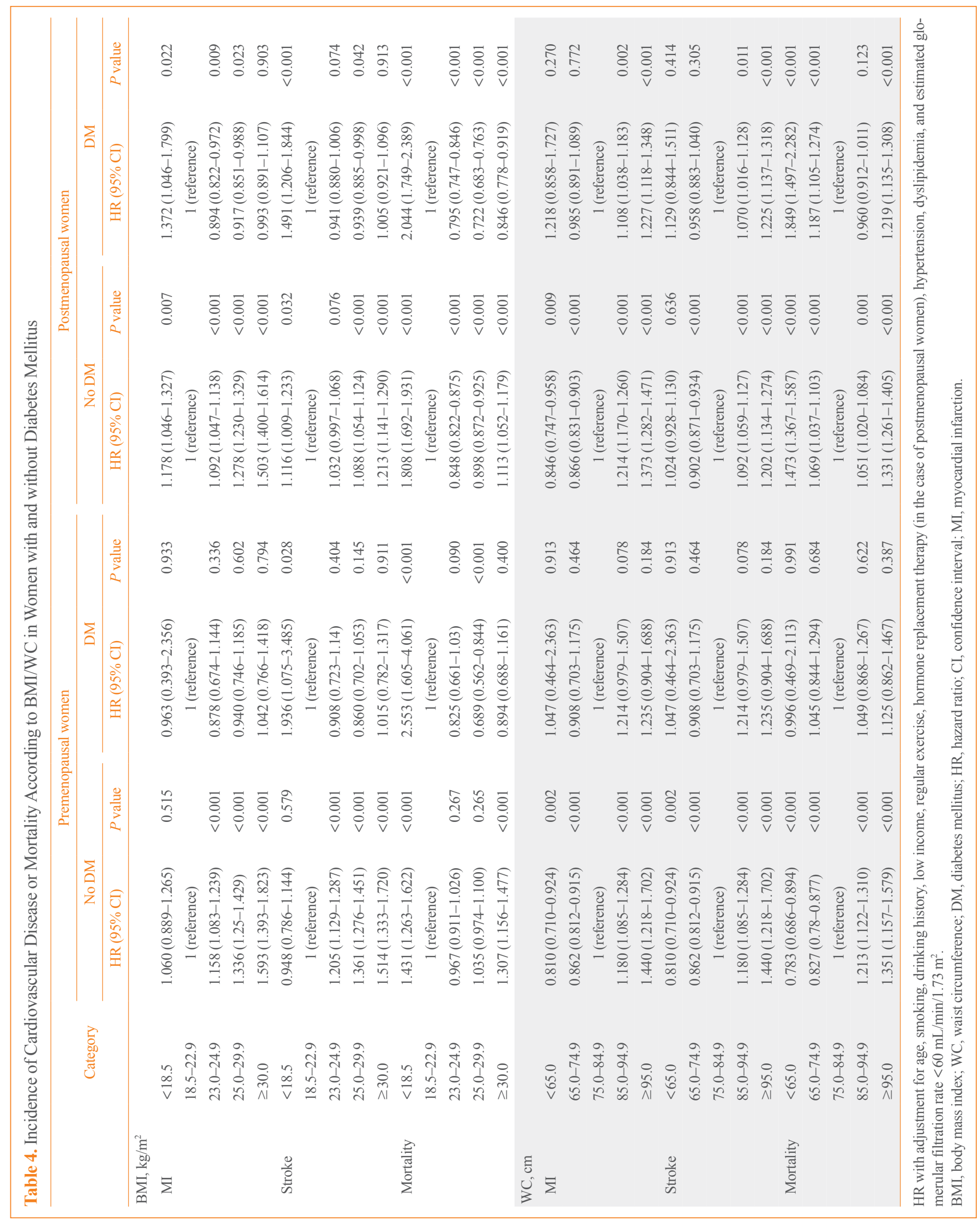



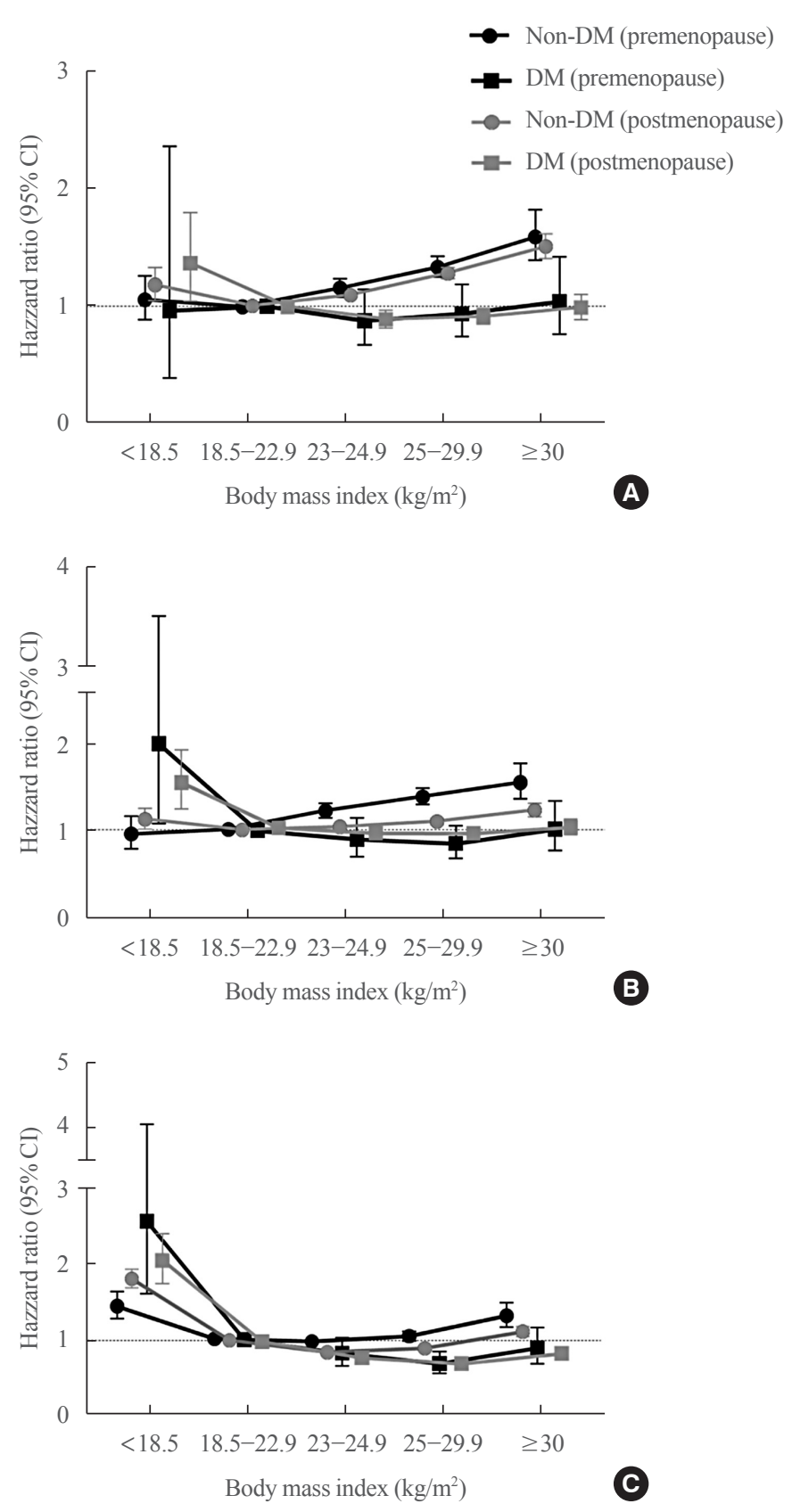

Fig. 3. The risk of myocardial infarction, stroke, and mortality during the follow-up period according to body mass index, diabetes mellitus (DM), and menopausal status. Hazard ratios for myocardial infarction (A), stroke (B), and mortality (C) according to body mass index after adjustment for age, smoking history, alcohol consumption, regular exercise, low income, hypertension, dyslipidemia, and chronic kidney disease in premenopausal (black) and postmenopausal (grey) women with (square) and without DM (circle). CI, confidence interval.

WC ( $<85 \mathrm{~cm}$ ), women with WC 65.0 to $74.9 \mathrm{~cm}$ had a lower risk of MI and stroke compared to those with WC 75.0 to 84.9 $\mathrm{cm}$, in both the premenopausal and postmenopausal groups (Supplemental Table S4).

The nadir of mortality was found in those with WC 65.0-74.9 and $75.0-84.9 \mathrm{~cm}$ in premenopausal and postmenopausal women, respectively (Supplemental Table S4). A U-shaped relationship with mortality was also found for WC: the risk of mortality was significantly increased for those with $\mathrm{WC} \geq 85.0$ and $\geq$ $95.0 \mathrm{~cm}$ among premenopausal and postmenopausal women, respectively, as well as for those with $\mathrm{WC}<65.0 \mathrm{~cm}$ (Fig. 2F). Among subjects with comorbidity, the risk of mortality in those with WC $<65.0 \mathrm{~cm}$ was more prominent both in the premenopausal and postmenopausal women compared to those in subjects without comorbidity (HR, 1.477; 95\% CI, 1.232 to 1.770 ; and $\mathrm{HR}, 1.665 ; 95 \% \mathrm{CI}, 1.487$ to 1.865 , in the premenopausal and the postmenopausal women, respectively) (Table 3, Supplemental Fig. S2C, D).

Stratified analysis according to DM status showed that in the case of premenopausal women without diabetes, a linear trend of HR according to WC was found ( $P$ for trend $<0.001$ ); women with WC $<65.0 \mathrm{~cm}$ exhibited the lowest mortality (HR, $0.783 ; 95 \%$ CI, 0.686 to 0.894 ) (Table 4 ).

\section{DISCUSSION}

Using a nationwide health examination database and claims data covering $97.0 \%$ of the population in Korea, we found that the risk of MI during the 10-year follow-up period was significantly increased when BMI was $\geq 23 \mathrm{~kg} / \mathrm{m}^{2}$ (overweight range) at baseline, irrespective of menopausal status. The risk of stroke during the same period significantly increased when BMI $\geq 23$ and $\geq 25 \mathrm{~kg} / \mathrm{m}^{2}$ in the premenopausal and postmenopausal women, respectively. However, the presence of DM, rather than other comorbidities such as cancer or COPD, attenuated the risk of MI and stroke associated with being overweight or obese; there was similar or significantly lower incidence of MI or stroke in those above the reference range of BMI compared to those in the normal range in women with DM.

The current study replicated the J-shaped relationship between BMI and mortality in postmenopausal women; in this group, those with BMI 23.0 to $24.9 \mathrm{~kg} / \mathrm{m}^{2}$ (overweight) showed the lowest mortality. In postmenopausal women, those with BMI 25.0 to $29.9 \mathrm{~kg} / \mathrm{m}^{2}$ (obesity) also had a significantly lower mortality compared to those with normal weight. In premenopausal women, the nadir of the risk of mortality was also found in those who were overweight; however, this was not statistically different from those with normal BMI. The mortality in the 
premenopausal women increased significantly from obesity class II, that is, BMI $\geq 30 \mathrm{~kg} / \mathrm{m}^{2}$. Even for premenopausal women without comorbidity, the same trend in the association between BMI and mortality was replicated. However, age stratification demonstrated that the lower mortality found in overweight and obese women was attenuated by young age.

Age is an important determining factor in the association between BMI and overall mortality [3,4]. A prospective study of 14 years showed that mortality in overweight women was increased only in those aged $<65$ years; there was no difference in the mortality rate between women who are overweight and those who are normal weight in women aged $\geq 65$ years [3]. Similarly, another study also confirmed that being overweight was an independent risk factor for the overall mortality only in those aged $<60$ years [4].

Contrasting overall mortality, obesity or overweight have been reported to increase the risk of CVD [19], and the current study results also support this. In the current study, obesity was an independent risk factor for MI or stroke, irrespectively of menopausal status. Among CVD, MI or heart failure was more highly associated with obesity compared to stroke [19]; this may explain the lack of increase of risk of stroke by obesity in several subgroups in the current study, such as postmenopausal women with comorbidities.

A pooled longitudinal cohort study reported that being overweight and obesity were independent risk factors for cumulative lifetime incident CVD events and CVD death [19]. By contrast, non-CVD death was lowered in overweight and obese people [19], which might explain the lower overall mortality in the obese and overweight population, despite their high CVD risk, compared to those in the normal-weight class in the current study. In addition, among patients with pre-existing CVD $[1,20]$ or heart failure [21], being overweight lowered the CVD mortality as well as overall mortality during the follow-up period. In contrast, in individuals with good cardiorespiratory function, there was no benefit from being overweight or obese [22]. The current study also confirmed this through the stratification according to the presence of comorbidities; in addition, even being in obesity class II did not increase the risk of mortality in those with comorbidities, irrespective of menopausal status.

The current study showed the presence of DM, rather than other comorbidities such as cancer or COPD, attenuated the risk of MI and stroke associated with being overweight or obese. In previous prospective cohort studies, it was found that weight gain before the diagnosis of DM increased the risk of CVD; however, weight gain after the diagnosis of DM was not associ- ated with risk of CVD $[5,6]$, which might be due to the fact that after the development of DM, insulin resistance and the associated CVD risk is too high to be affected by any additional weight gain. In addition, hypertension or dyslipidemia, which frequently accompany DM as well as obesity, play more important roles in the development of CVD compared to obesity [23,24].

In the case of WC, a linear increasing trend with MI and stroke was found, irrespective of menopausal status, which corresponded to the results of a previous report in the European population [25]. WC can discriminate CVD outcomes better than BMI [25], and the effect of WC on clinical outcomes was maintained across diverse BMI categories [26,27]. In the current study, even in those within the normal range of $\mathrm{WC}(<85$ $\mathrm{cm}$ ), women with WC 75.0 to $84.9 \mathrm{~cm}$ had a higher risk of MI and stroke compared to those with WC 65.0 to $74.9 \mathrm{~cm}$. Stratified analysis according to DM status also confirmed that abdominal obesity (WC $\geq 85 \mathrm{~cm}$ ) increased the risk of $\mathrm{MI}$ in women. A J-shaped association with mortality was also found for WC; however, there was no significant increment of mortality in the normal range of WC (75.0 to $84.9 \mathrm{~cm})$.

The current study has several limitations. First, the CVD events during the follow-up period were assessed using claims data. Claims data might underestimate the real incidence of CVD, especially in the case of ischemic stroke [28]. In addition, it provides limited information on disease severity. However, the definitions for CVD used in the current study were validated in a previous study in Korea; their sensitivity and positive predictive values for the claims data were reported to reach $90 \%$ [11]. Furthermore, the NHIS in Korea covers the claims of $97.0 \%$ of the population, thus proving invaluable in the estimation of the effect of obesity parameters on clinical outcomes in the entire Korean population; this also helps to build a cutoff value for the obesity parameter for public health in Korea. Second, we did not have cause-specific mortality data, which makes it more difficult to explain the different effect of overweight or obesity status on CVD events and overall mortality. Finally, the median duration of follow-up of the current study was 9.3 years, and follow-up duration affects the impact of BMI on mortality. The underweight group had been reported to have increased risk for CVD mortality and overall mortality [1], as is in the current study, but this was attenuated with longer-term follow-up [4]. In addition, the long-term benefit of obesity on CVD mortality in those with pre-existing CVD disappeared after 5 years of follow-up [20]. Further long-term studies should be performed, especially in the younger population, to estimate 
an optimal BMI or WC for long-term benefit.

In conclusion, for CVD prevention, the current reference range of BMI (18.5 to $22.9 \mathrm{~kg} / \mathrm{m}^{2}$ ) may be optimal irrespective of menopausal status. However, in diabetic women or women aged $\geq 60$ years, a less stringent cutoff for obesity can be applied. To estimate the risk of CVD events, WC might be more suitable than BMI in those with DM or comorbidities, especially in postmenopausal women. In postmenopausal women, being overweight and obese reduced the mortality rate significantly even in those without comorbidities, which suggests that consideration for menopausal status as well as age should be required for BMI cutoff for obesity management.

\section{CONFLICTS OF INTEREST}

No potential conflict of interest relevant to this article was reported.

\section{ACKNOWLEDGMENTS}

This work was supported by a multidisciplinary research grantin-aid from the Seoul Metropolitan Government Seoul National University (SMG-SNU) Boramae Medical Center (04-20210030).

\section{AUTHOR CONTRIBUTIONS}

Conception or design: K.H., M.K.M. Acquisition, analysis, or interpretation of data: S.H.P., K.H., B.K.K. Drafting the work or revising: B.K.K., M.K.M. Final approval of the manuscript: B.K.K., S.H.P., K.H., B.K.K.

\section{ORCID}

Bo Kyung Koo https://orcid.org/0000-0002-6489-2656

Min Kyong Moon https://orcid.org/0000-0002-5460-2846

\section{REFERENCES}

1. Romero-Corral A, Montori VM, Somers VK, Korinek J, Thomas RJ, Allison TG, et al. Association of bodyweight with total mortality and with cardiovascular events in coronary artery disease: a systematic review of cohort studies. Lancet 2006;368:666-78.

2. Jee SH, Sull JW, Park J, Lee SY, Ohrr H, Guallar E, et al. Body-mass index and mortality in Korean men and women.
N Engl J Med 2006;355:779-87.

3. Calle EE, Thun MJ, Petrelli JM, Rodriguez C, Heath CW Jr. Body-mass index and mortality in a prospective cohort of U.S. adults. N Engl J Med 1999;341:1097-105.

4. Berrington de Gonzalez A, Hartge P, Cerhan JR, Flint AJ, Hannan L, MacInnis RJ, et al. Body-mass index and mortality among 1.46 million white adults. N Engl J Med 2010; 363:2211-9.

5. Cho E, Manson JE, Stampfer MJ, Solomon CG, Colditz GA, Speizer FE, et al. A prospective study of obesity and risk of coronary heart disease among diabetic women. Diabetes Care 2002;25:1142-8.

6. Kim MK, Han K, Koh ES, Kim ES, Lee MK, Nam GE, et al. Weight change and mortality and cardiovascular outcomes in patients with new-onset diabetes mellitus: a nationwide cohort study. Cardiovasc Diabetol 2019;18:36.

7. Kannel WB, Hjortland MC, McNamara PM, Gordon T. Menopause and risk of cardiovascular disease: the Framingham study. Ann Intern Med 1976;85:447-52.

8. Carr MC. The emergence of the metabolic syndrome with menopause. J Clin Endocrinol Metab 2003;88:2404-11.

9. Gordon T, Kannel WB, Hjortland MC, McNamara PM. Menopause and coronary heart disease. The Framingham Study. Ann Intern Med 1978;89:157-61.

10. Koo BK, Lee CH, Yang BR, Hwang SS, Choi NK. The incidence and prevalence of diabetes mellitus and related atherosclerotic complications in Korea: a National Health Insurance Database Study. PLoS One 2014;9:e110650.

11. Park J, Kwon S, Choi EK, Choi Y, Lee E, Choe W, et al. Validation of diagnostic codes of major clinical outcomes in a National Health Insurance database. Int J Arrhythm 2019; 20:1-7.

12. World Health Organization; Regional Office for the Western Pacific. The Asia-Pacific Perspective: Redefining Obesity and its Treatment. 2000. Sydney: Health Communications; 2000. p. 15-21.

13. Seo MH, Lee WY, Kim SS, Kang JH, Kang JH, Kim KK, et al. 2018 Korean Society for the Study of Obesity Guideline for the management of obesity in Korea. J Obes Metab Syndr 2019;28:40-5.

14. WHO Expert Consultation. Appropriate body-mass index for Asian populations and its implications for policy and intervention strategies. Lancet 2004;363:157-63.

15. Lee SY, Park HS, Kim DJ, Han JH, Kim SM, Cho GJ, et al. Appropriate waist circumference cutoff points for central obesity in Korean adults. Diabetes Res Clin Pract 2007;75: 
$72-80$.

16. Levey AS, Inker LA, Matsushita K, Greene T, Willis K, Lewis E, et al. GFR decline as an end point for clinical trials in CKD: a scientific workshop sponsored by the National Kidney Foundation and the US Food and Drug Administration. Am J Kidney Dis 2014;64:821-35.

17. Hwang JH, Lee JP, Kim CT, Yang SH, Kim JH, An JN, et al. Urinary periostin excretion predicts renal outcome in IgA nephropathy. Am J Nephrol 2016;44:481-92.

18. Choi EK. Cardiovascular research using the Korean National Health Information Database. Korean Circ J 2020;50:75472.

19. Khan SS, Ning H, Wilkins JT, Allen N, Carnethon M, Berry JD, et al. Association of body mass index with lifetime risk of cardiovascular disease and compression of morbidity. JAMA Cardiol 2018;3:280-7.

20. Wang ZJ, Zhou YJ, Galper BZ, Gao F, Yeh RW, Mauri L. Association of body mass index with mortality and cardiovascular events for patients with coronary artery disease: a systematic review and meta-analysis. Heart 2015;101:16318.

21. Zhang J, Begley A, Jackson R, Harrison M, Pellicori P, Clark AL, et al. Body mass index and all-cause mortality in heart failure patients with normal and reduced ventricular ejection fraction: a dose-response meta-analysis. Clin Res Cardiol 2019;108:119-32.

22. De Schutter A, Lavie CJ, Patel DA, Milani RV. Obesity paradox and the heart: which indicator of obesity best describes this complex relationship? Curr Opin Clin Nutr Metab Care 2013;16:517-24.

23. Stevens RJ, Kothari V, Adler AI, Stratton IM; United King- dom Prospective Diabetes Study (UKPDS) Group. The UKPDS risk engine: a model for the risk of coronary heart disease in type II diabetes (UKPDS 56). Clin Sci (Lond) 2001; 101:671-9.

24. Goff DC Jr, Lloyd-Jones DM, Bennett G, Coady S, D’Agostino RB, Gibbons R, et al. 2013 ACC/AHA guideline on the assessment of cardiovascular risk: a report of the American College of Cardiology/American Heart Association Task Force on Practice Guidelines. Circulation 2014; 129(25 Suppl 2):S49-73.

25. Iliodromiti S, Celis-Morales CA, Lyall DM, Anderson J, Gray SR, Mackay DF, et al. The impact of confounding on the associations of different adiposity measures with the incidence of cardiovascular disease: a cohort study of 296535 adults of white European descent. Eur Heart J 2018;39:151420.

26. Cho GJ, Yoo HJ, Hwang SY, Choi J, Lee KM, Choi KM, et al. Differential relationship between waist circumference and mortality according to age, sex, and body mass index in Korean with age of 30-90 years; a nationwide health insurance database study. BMC Med 2018;16:131.

27. Kim YH, Kim SM, Han KD, Jung JH, Lee SS, Oh SW, et al. Waist circumference and all-cause mortality independent of body mass index in Korean population from the National Health Insurance Health Checkup 2009-2015. J Clin Med 2019;8:72.

28. Ono Y, Taneda Y, Takeshima T, Iwasaki K, Yasui A. Validity of claims diagnosis codes for cardiovascular diseases in diabetes patients in Japanese administrative database. Clin Epidemiol 2020;12:367-75. 